\title{
Terremotos recordados, temblores olvidados. Interpretaciones sobre los orígenes de la memoria telúrica en Chile ${ }^{1}$
}

\author{
Mauricio Onetto Pavez ${ }^{2}$
}

\begin{abstract}
RESUMEN
El presente artículo abordará algunos de los factores y situaciones que determinaron, en cierta medida, la manera de comprender, recordar y representar el tema telúrico por parte de los pobladores de Chile durante los siglos XVI-XVIII. Por lo general, los estudios históricos han dado una mayor relevancia a subordinar lo anterior al aspecto religioso que era muy importante en esos años, sin embargo, se exhibirá cómo influyeron aspectos que fueron más allá de esta esfera, entre los que destacan, las percepciones e imágenes que se tenían sobre el territorio chileno y los diferentes intereses económicos y políticos que tenían las autoridades en aquella época. Por otra parte, el texto buscará comprobar la importancia de incluir dentro de los análisis de las catástrofes, asociados siempre a otras disciplinas, la perspectiva histórica.
\end{abstract}

Palabras clave: Terremotos, Chile, Historia, seguridad, riesgo, memoria, olvido.

\begin{abstract}
This article will address some of the factors and situations that determined, to some extent, how telluric events are understood, remembered, and represented by Chilean society from the sixteenth to the eighteenth centuries. Generally, historical studies have greatly minimized the importance of these events, favoring instead aspects related to religious beliefs that were of great significance at the time, however, in this paper other influencing factors beyond religious arguments are examined, most notably, perceptions and images held of the Chilean territory and the various economic and political interests of authorities at the time. Moreover, this study investigates the importance of including the historical perspective, always associated with other disciplines, in the analysis of disasters.
\end{abstract}

Key words: earthquakes, Chile, History, protection, risk, memory, forgetfulness

1 Este artículo forma parte de nuestro proyecto "Impacto histórico-mediático de las catástrofes telúricas ocurridas en Chile entre los años 1906 y 2010", financiado por CONICYT FONDECYT POSTDOCTORADO No 3140413. Este artículo además contó con el apoyo del Núcleo CEUT del programa ICM del Ministerio de Economía, Fomento y Turismo.
Artículo recibido el 13 de enero de 2014, aceptado el 20 mayo de 2014 y corregido el 7 de agosto de 2014.

2 Facultad de Patrimonio Cultural y Educación, Universidad SEK (Chile). E-mail: maonetto@gmail.com 
La historia sísmica chilena ha sido trabajada efímeramente tanto por historiadores como por estudiosos vinculados a la geografía, geología y la física. En la actualidad, debido a los eventos telúricos ocurridos desde principios de la década anterior y luego de los últimos terremotos registrados desde el año 2010 esto se ha acrecentado $^{3}$. Sin embargo, aún no se logra vislumbrar un interés más profundo por reflexionar sobre las consecuencias generales que han tenido estos acontecimientos en el devenir histórico de Chile ${ }^{4}$. Tampoco se han propuesto interpretaciones para entender ciertas particularidades como, por ejemplo, que solamente en Chile se pueda establecer una diferencia tan marcada en el vocabulario relacionado a los movimientos telúricos, entre palabras como temblor, sismo y terremoto. En otras palabras, lo que intentamos señalar es que se ha comenzado a meditar sobre una historia sísmica sobre una base que no existe, que no ha sido lo suficientemente estudiada ni contrastada. La simple suma de terremotos no da mérito a ello.

Desde la disciplina de la historia, durante los últimos años se pueden reconocer una serie de publicaciones que demuestran este nuevo interés, aunque se trata de trabajos monográficos, muy específicos (sobre los efectos de un solo terremoto o los problemas de un área determinada). Esto no permite examinar los pilares característicos y

3 Ver el caso de la Revista de Geografía Norte Grande en 2012, titulado "Tsunamis y terremotos" o de la Revista INVI, Separata, No 68, 2010. Asimismo, se pueden distinguir la aparición de diferentes grupos de investigación financiados por el Estado, por medio de Conicyt o por el Ministerio de Economía, Fomento y Turismo de Chile con los ICM. Algunos casos son el Centro de Investigación para la Gestión Integrada de Desastres Naturales (CIGIDEN) dirigido por investigadores de la PUC, en el cual colaboran otras tres universidades más; El proyecto FONDECYT No 1120406, titulado "Espacio público / Espacio privado. Destrucción y reconfiguración de los límites cotidianos del habitar en la experiencia post-terremoto"; El proyecto Núcleo Milenio que nace luego del terremoto de 2010 en Talca para conformar el Centro de Estudios Urbano-Territoriales para la región del Maule, Universidad Católica del Maule, Facultad de Ciencias Sociales y Económicas, entre otros.

4 Al respecto, nuestra tesis de doctorado, aún inédita, abordó algunas de estas temáticas Onetto (2013). globales, como tampoco se puede observar el impacto histórico de estos desastres en la larga duración o desde una perspectiva que reflexione lo descrito como "nacional" (Onetto, 2011 (b)). La religiosidad, las descripciones sobre la destrucción y el relato de algunas medidas estatales vinculadas a la organización de las formas de sociabilidad se pueden encontrar entre estos estudios (De Ramón, 1998; Rojo, 2009; Palacios, 2009; Valenzuela, 2007 y 2012). A pesar de lo anterior, también se pueden ver nuevas motivaciones que han permitido que las preguntas en torno a los sismos comiencen a ser más sofisticadas, lo que promueve casi automáticamente una diversificación de las temáticas (Riquelme y Silva, 2011).

En cuanto a la perspectiva de las ciencias consideradas como "duras", este auge también ha prosperado, pero aún lejos de disciplinas como la historia con la cual se podrían complementar o compartir las informaciones. En efecto, las instituciones relacionadas a los registros sísmicos solo han apuntado a estudiarlos desde un punto de vista cuantitativo. El Servicio de Sismología de Chile -creado luego del terremoto de 1906-, ha establecido los hitos de esta historia sísmica, exclusivamente, enumerando aquellas sacudidas identificadas como "históricas", pero en ningún caso recurriendo a un respaldo historiográfico de carácter científico para justificar sus afirmaciones. En efecto, la noción de lo histórico queda, para este caso, definida por "expertos" de otras áreas o por funcionarios del Estado. Asimismo, queda limitada a lo sucedido y percibido, exclusivamente, en un determinado presente - presentisme ${ }^{5}$.

De hecho, gran parte de lo considerado como historia sísmica está resumido en un recuadro titulado "Sismos Importantes y/o Destructivos", el cual se encuentra en la página web de la institución. Con ello, solo han

\footnotetext{
5 Este término fue creado por el historiador Francois Hartog. El estudioso plantea, como uno de los males de las sociedades actuales, que exista el deseo de autosatisfacer las experiencias de lo humano únicamente a partir del horizonte histórico definido en el presente, el cual descuida, según él, la relación con el pasado y el avenir (Hartog, 2003).
} 
quedado registrados aquellos movimientos que se "supone" han tenido una magnitud ms mayor o igual a 7.0, lo que no quiere decir que esto entró automáticamente en el recuerdo de los habitantes ${ }^{6}$. Con esto nos referimos, sobre todo, a lo ocurrido entre los siglos XVI y XVIII.

En efecto, en este recuadro se precisan, fechas, horas, latitudes, profundidades, efectos secundarios, como también magnitudes como la de Richter. Sin embargo, este resumen gráfico fue estructurado a partir de indicios que no se encuentran precisados por ninguna de las fuentes citadas. Tanto el Departamento de Geofísica de la Universidad de Chile (GUC) como el National Earthquake Information Center (NEIC) de EEUU7, encargados de organizar la información para Chile, no tienen en ninguno de sus sitios web, ni menos en sus archivos, un trabajo de carácter científico que sustente estas ideas, al menos, para los años en que se concentrará nuestro estudio (siglos XVI-XVIII). Es más, mutuamente se citan, pero no respaldan sus afirmaciones. Esto se puede notar, por ejemplo, en la sección Historic Earthquakes del NEIC, en donde el único terremoto que se distingue para Chile durante los siglos que estudiamos es el terremoto de 1730. De hecho, se afirma sucintamente que afectó a una serie de ciudades como Coquimbo, Illapel, La Serena, Petorca, Santiago y Valparaíso, y que se caracterizó por provocar un maremoto que se pudo apreciar desde el Perú hasta el noroeste de Japón (Honshu) ${ }^{8}$. A su vez, se agrega que su epicentro fue Valparaíso y que murieron solo cinco personas. Pese a proveer estas informaciones, que tienen concordancia en alguno de los puntos planteados por los testimonios de la época, como en la extensión del movimiento, no fue así en la mayoría de los casos. El tópico del epicentro difiere de lo que los propios habitantes detallaron para

6 En la actualidad, el cuadro al que cual nos referimos se encuentra en la sección "infórmate/terremotos" de la página web del Servicio de Sismología: http:// www.sismologia.cl/. Este mismo registro existió bajo otro formato hasta inicios del 2013.

7 Trabaja a la par con el World Data Center y el NOAA's National Geophysical Data Center (NGDC).

8 http://earthquake.usgs.gov/earthquakes/world/historical.php/ (consultado el 27 de octubre, 2011) aquel entonces, o de la cantidad de muertos presentada que no fueron cinco, sino que se contabilizaron decenas.

Sin duda, hay una valorización, una necesidad de realizar o de dejar expuesta una "Historia". Hay una búsqueda de revalorizar un tema que se presenta como periódico o cuantitativamente interesante a tener en cuenta, tanto desde el plano científico como dentro de un marco nacional-institucional. Sin embargo, para este caso pensamos que los vectores utilizados para generar los resultados se sobrevaloraron con tal de obtener ciertos márgenes y así encontrar un resultado "científico" que pudiese legitimar algunas constantes que se especulan desde el mundo de la física. De hecho, para realizar los cálculos -como las magnitudes de Richterse utilizaron herramientas matemáticas a partir de la lectura de algunas fuentes primarias expuestas por los historiadores del siglo XIX en sus libros, los que no hicieron un análisis crítico de ellas. Ahora bien, estas fuentes citadas son documentos que, hasta el día de hoy, se encuentran dispersos en algunos de los archivos chilenos, y cuya particularidad es la de haber sido considerados por estudiosos que en esos tiempos representaban la visión del Estado, es decir, eran los encargados de escribir la historia oficial de Chile. En efecto, fueron ellos los que habrían decidido incluir a los terremotos como parte de los eventos fundadores de la nación (cf. López, 2011).

Por ejemplo, para los años en lo que se centrará este estudio (siglos XVI-XVIII), no se diferenció ninguna de las realidades materiales de los habitantes, como tampoco se hizo distinción de los contextos desde donde se efectuaron las calificaciones de los propios testimonios. Incluso, se integraron otros territorios que para ese entonces no pertenecían o ni siquiera eran asociados a la "tierra de Chile", como el caso de los terremotos que se identifican para los años de 1604 y 1615. Esta búsqueda de instaurar una "Historia" a partir exclusivamente de una numeración de los sismos en Chile, nos lleva a preguntarnos ¿qué historia se quiere retratar con estas informaciones? 
En ningún caso desmerecemos las observaciones científicas y la seriedad que se tuvo para realizar la planilla, sobre todo, cuando sabemos que gran parte de las informaciones retenidas fueron trabajadas por especialistas en sismología de reputación mundial como lo fue Fernand Montessus de Ballore (Montessus Ballore, 1912). No obstante, aún vemos lejana la opción de completar este recuadro si no se realiza una lectura que busque ir más allá de la simple notación, o que solo desee generar un modelo de simple comprensión. En efecto, para aquellos tiempos las descripciones de los sismos estuvieron determinadas por una serie de factores que determinaron los relatos y que fueron de tipo material, religioso, espacial como también de orden administrativo (disposiciones de la Monarquía). Por ejemplo, gran parte de las descripciones sobre los sismos estuvieron marcadas por la ideología religiosa del período. Por tanto, los colores, olores y otros vectores considerados en ellas no deben ser considerados al pie de la letra, ya que muchas veces el agua negra o roja -sangrienta- que brotaba de la tierra, era un símbolo de una concepción escatológica (Onetto, 2011a). En este sentido, es relevante recordar que gran parte de estos factores se estructuraron, en su mayoría, desde fuera de Chile, por tanto, el escenario sísmico resulta más espinoso de lo que podría ser un cálculo matemático de las consecuencias producidas por la tierra.

\section{La catástrofe como acontecimiento: la importancia de la perspectiva histórica}

"De hecho, todo lo que amenaza la memoria, provoca pánico" ${ }^{\prime \prime}$.

Todo lo que circunda a una catástrofe es difuso. Desde las consecuencias que deja a los conceptos asociados a ella. Por ejemplo, el riesgo en todas sus acepciones y elementos que ayudan a comprenderlo lo develan como un concepto con cualidades potenciales (ar-

\footnotetext{
9 (Todorov, 1995). Traducción propia.
}

tificiales $\left.{ }^{10}\right)$ que conviven con lo real ${ }^{11}$ y que pueden variar de un individuo a otro (Albouy, 2002: 16). A esto se suma, la dificultad de que las catástrofes no tienen "concordancia, ni temporal, ni espacial, ni en intensidad" (Dauphine, 2004:16) y la cantidad de orígenes etimológicos (Collas-Heddeland et al., 2004; Fantini, 2006; O'dea, 2008; Walter, 2008). Todo esto deja inciertos tanto los modos de cómo utilizarlas por las ambigüedades que presentan (Pigeon, 2002), como también las consecuencias que pueden tener en un orden político ${ }^{12}$.

A pesar de la inestabilidad y dificultades que pueden presentar los escenarios catastróficos, consideramos que a partir de estos eventos se puede evaluar la percepción que una sociedad tiene sobre su devenir histórico. Las reacciones ante una catástrofe pueden ser, como señala François Walter "indicadores de comprensión del mundo" (Walter, 2008:12) que ayudan a develar, entre otras cosas, las tensiones sociales existentes de una sociedad (García, 1996). Esto es lo que permite construir objetos de estudios en torno a ellas (Girard \& Langumier 2006) ${ }^{13}$.

${ }^{10}$ Mary Douglas señala que el riesgo "is not a thing, it is a way of thinking, and a highly artificial contrivance at that" (Douglas, 1992: 46). Dentro de esta misma línea subjetiva de la catástrofe, Jean Paul Bozonnet la define de la siguiente manera: "Definido socialmente, el estado de catástrofe es eminentemente subjetivo : el juicio de esto, depende evidentemente de los intereses materiales en juego, pero trae consigo lo afectivo y elementos del imaginario" (Bozonnet, 1994: 29). Traducción propia.

11 Patrick Pigeon es categórico cuando señala que la noción de riesgo consta de un doble componente: "aquella referida al daño potencial y otra que contempla el daño efectivo, la cual puede ser socialmente identificada" (Pigeon, 2002: 460-461)

${ }^{12}$ Con respecto a la forma como estos eventos afectan a un orden político, Jean Braudillard indica que: "El accidente ha devenido en una paradoja de la necesidad: posee la fatalidad de este y la indeterminación de la libertad [...] Una catástrofe natural es un peligro para el orden establecido, no solo por el desorden que provoca, sino que además por el golpe que provoca a toda " racionalidad » soberana, política" (Braudillard, 1975: 22). Traducción propia.

13 Otros textos que hablan sobre estos tópicos y la importancia del estudio por parte de las Ciencias Sociales son los de: (Quenet, 1999, 2009; MassardGuilbaud, 2007; Weiner, 2005; White, 1999). Otro tipo de reflexiones más bien filosóficas son (Dupuy, 2002; Jeudy, 1990; Virilio, 2005, 2007). 
Es por ello que pensamos que las catástrofes tienen relación directa con la memoria y con la historia. Son acontecimientos que conectan una gama de sentidos acumulados, olvidados, imaginados con materialidades y paisajes destruidos y/o esperados. Por tanto, son más bien instancias en donde una serie de posibilidades encontraron lugar, en un determinado presente y de manera violenta, transformándose en una "trampa mortal", como diría Signorelli (Signorelli, 1992: 7).

Lo que se quiebra cuando se produce una catástrofe, es la imagen que de ella misma se tenía, puesto que da realidad a un acontecimiento que solo se consideraba como posible o virtual, pese a que sabemos que una catástrofe no puede reducirse a una dimensión accidental y factual solamente (Clavandier, 2011). Paradójicamente la catástrofe da vida y ayuda a forjar historias; da vida a aquello que solo podía ser imaginado, a aquello que solo podía ser considerado como un riesgo en un territorio ${ }^{14}$, pero también permite transmitir, crear y realizar transacciones de sentidos (Quéré, 2006 ). Por tanto, es una conceptualización, histórica, totalmente relacionado con lo humano y que puede ser estudiado. Es por esta razón, que las catástrofes no pueden ser consideradas como "naturales", incluso, aquellas que sean producto algún fenómeno natural: "la naturaleza no conoce de catástrofes" (Walter, 2008: 16).

En ningún caso se podría dar una fórmula sobre cómo trabajar las catástrofes. Quizás, se pueden dar coordenadas a partir de la "urgencia" del evento, pero no contabilizar los tiempos que conviven en ella (Clavandier, 2004: 37). De hecho, ciertas explicaciones con respecto a las catástrofes y riesgos establecen conexiones temporales de "corta duración" cuando es probable que parte de las respuestas sobre cómo salir del caos de

\footnotetext{
14 Valerie November precisa : "El riesgo es un componente intrínseco del territorio, que tiene una o varias logicas espaciales. El problema es que el territorio es más bien considerado como un espacio-soporte de riesgos, cuando debemos observarlo como algo capaz de interactuar con los riesgos (...) El riesgo es la mayor parte del tiempo considerado como externo, no dotado de una dinámica espacial interna, es decir, no insertada en el territorio o dinámica territorial". (November, 2002 :35). Traducción propia.
}

una catástrofe provengan de otra época o correspondan a diferentes miedos que fueron diluyéndose en el tiempo. La catástrofe reconfigura la tensión temporal de un grupo al romper el "diálogo" con los tiempos, reduce pasado y futuro a un mismo momento. Por tanto, no todo debería evaluarse desde el presente.

En cuanto a la memoria, la catástrofe descansa sobre un paradigma social, sobre un proyecto que se rompe. Es un espacio que se designa como "seguro" el que se pone en tela de juicio cuando esta sucede. Por esta razón es colectiva, porque no se trata de un espacio personal, sino de un espacio de seguridad fracturado en el cual una comunidad se identificaba. A su vez, la consideramos colectiva porque requieren del reconocimiento de "otros", exteriores a la catástrofe, para reconocerse como tal. Por ello, hay cierta propiedad de universalidad inherente a cada catástrofe.

En relación a lo anterior, cabe precisar que el colectivo se descubre en el acontecimiento, pero la memoria no se vuelve colectiva (cf. Halbwachs, 1997). Si fuera este el caso, estaríamos hablando más bien de usos -políticos (Hartog, 2001)- de un recuerdo, discurso, etc., sobre el acontecimiento, que es lo que muchas veces se impone como recurso. "Usos" que claramente se intentan superponer por parte de uno de los grupos, para satisfacer sus intereses por medio de una "ilusión holística", es decir, generar un discurso que represente el hechos que todos son parte homogénea e integrada de un mismo grupo (Candau, 2005: 79-80).

Desde esta perspectiva, no escatima en distinguir ni los cruces, los quiebres, ni menos las superposiciones de memorias que se pueden haber producido en un mismo grupo tras el evento. Con este tipo de perspectiva solo florece una visión uniforme, que hace pensar que fue creada "por todos" y que es "para todos", lo que resta riqueza al contenido de las memorias que conviven y convivieron, quitando la posibilidad de aprehender el acontecimiento. A su vez, esto trae como consecuencia que el tema de las memorias en relación a este tipo de sucesos se singularice y se establezca una tensión, exclusivamente, con el pasado. Por tanto, memoria oficial, 
colectiva, nacional, o cualquier otro adjetivo, deben ser reflexionadas como respuestas a esa dispersión inherente que poseen las memorias y que contradice ciertos "órdenes" temporales que desean establecer unos sobre otros cuando se toman este tipo de eventos.

Incluso, si se reconoce un acontecimiento en particular como catástrofe esto no basta para identificar de qué, sobre qué o a quién se habla, ni menos los "regímenes de historicidad" que están vinculados. Siempre se necesitan otros elementos, otros discursos, imágenes o experiencias para hablar de la dimensión de una catástrofe, porque -como dice Gilbert- "elle est partout et nulle part en particulier" (Gilbert, 1998:157). Del mismo modo que se requiere de otros elementos para aclararlas, estos automáticamente hacen que sus fronteras espaciales y temporales se expandan. Así es, se forja no solo una historia sobre el evento, sino la historia de la recepción de este mismo (Jeudy, 2008: 20).

De hecho, aquellos conceptos asociados a las catástrofes sufren de esta misma expansión. Por más que el riesgo sea una construcción histórica ${ }^{15}$ y social (Acosta, 1993, 1996) aceptada por una comunidad, aún así escapa al control del grupo que lo creó o aceptó, puesto que sus formas de difusión en tanto posibilidad de daño pueden tocar lugares que no son parte de ese colectivo, es decir, la "dimensión espacial del riesgo" (Menoni, 1997) y los efectos de una misma catástrofe -"periferia del desastre" escapan a la comprensión de un solo grupo y, por tanto, el "testimonio del daño" debe considerarse como algo que tendrá una amplitud mayor de la esperada (Pigeon, 2002: 462).

A pesar de su amplitud temporal, los desastres se reconocen en la ruptura de lo material y corporal, pero ¿qué es lo que se rompe? ¿Son los paisajes? ¿Son los objetos materiales? ¿Es el miedo al desorden? En este sentido, la catástrofe no solamente nos

\footnotetext{
15 (Collas-Heddeland, 2004:16). Este autor muestra las variaciones de la etimología de la palabra riesgo a lo largo de los siglos, la cual varía según la lengua griega, latina y árabe. La definición primaria, habría estado asociada a los peligros que corrieron las primeras grandes empresas marítimas durante el siglo XIII.
}

permite verificar los efectos nocivos de un acontecimiento, sino más bien los puntos donde también se generan y acumulan las seguridades y se "develan (en sentido de desnudar) los elementos de la realidad imaginada" (Gilbert, 1998: 161-162).

Por este motivo hablar de historia sísmica debe ser un ejercicio vinculado con el conjunto general de cosas que suceden dentro de una sociedad. En este sentido, se requiere un ejercicio histórico de tipo "genealógico", es decir, un tipo de análisis cuyo horizonte sea plural, que no se preocupe de un origen, sino de posibles orígenes, de su esparcimiento, de sus contradicciones, de sus devenires y dimensiones. El ejercicio genealógico debe buscar la emergencia en su doble acepción y convertirse en una modalidad que nos permita presentar un tema difuso en su propia dispersión. Esta manera de reflexionar que profundiza en los vacíos, nos permitirá conocer los espacios del olvido (Foucault, 2001: 1008-1009).

\section{La importancia de los factores y contextos históricos de Chile, siglos XVI-XVIII}

Los orígenes de lo que podríamos señalar como historia sísmica chilena remontan a la llegada española sobre el territorio, es decir, el conocimiento de lo telúrico quedó encadenado a los registros escritos que se pueden encontrar desde esa época. La mirada de "los vencedores" fue la que finalmente construyó y delineó esta historia, ya que poco se sabe de las apreciaciones de los grupos nativos (cf. Petit-Breuilh, 2006). Ahora bien, las definiciones del tema telúrico estuvieron influidas por una serie de situaciones que no siempre -al menos durante el primer siglo de conquistatuvieron como centro la descripción de un terremoto. Reconocemos diferentes factores que afectaron la forma de afrontar o de dar a conocer este tópico, los cuales estuvieron relacionados tanto con temas políticos, económicos y sociales, como también con las nociones de riesgo y seguridad para la época.

Los terremotos, un nuevo problema para Chile

El jesuita Lorenzo de Arizabalo hacia 1660 escribió una relación que trató sobre el 
"Estado general del Reino de Chile". Fueron las autoridades de la Monarquía española quienes le habían pedido hacer este informe. El sacerdote no solo se sentía halagado por esta petición, sino que también autorizado. La experiencia de haber transitado por Chile debido a temas relacionados a la religión, le otorgó la autoridad para describir lo que ocurría en el territorio, aunque dejó en claro lo difícil que fue haber tomado la decisión de recorrer una tierra reconocida por sus riesgos: "Y aunque me causaba horror dar principio a tan largo camino, que pasa de tres mil leguas, por tan peligrosos golfos por climas y temples tan extraordinarios vencí el horror de tan largo camino"16. Chile se presentaba como una tierra de riesgos -idea consolidada durante el siglo $\mathrm{XVI}^{17}$-, pero como una atracción "dul$c^{\prime \prime}$ y misteriosa que lo hacía un lugar único. Su testimonio fue claro en esto:

"Mejor podre yo decir que si la traición puso a Chile en los riesgos, un rey padre la saco de ellos para gloria suya....Quien está en las garras de la tribulación como los que están en el reino de Chile aguardando la muerte, que es el menor mal y el mayor de un cautiverio bárbaro? Quien esta cercado de infieles, quien esta en medio de una nación perversa? Yo puedo decir de mi, cuando estaba en aquel reino que muchas veces cuando cerraba de noche mi puerta no tenia mas consuelo que

16 "Carta de Lorenzo de Arizabalo al Rey sobre el estado general de Chile. Sf (1660)", (Medina, 1898: 296).

17 Chile antes de ser Chile fue comprendido como un espacio de riesgo y catástrofe. Esto porque el territorio estuvo asociado desde principios del siglo XVI a diversos imaginarios ligados a la idea de una antípoda desconocida, un fin de mundo cuyo paso era el Estrecho de Magallanes. Esto cobró mayor fuerza con los hechos ocurridos durante la década de 1520, en donde se reconocen naufragios y la pérdida importante de hombres a causa de las inclemencias del tiempo y lo dificultoso de atravesar aquellas geografías. Por tanto, el territorio siempre estuvo asociado a una aventura peligrosa o riesgosa, en donde el factor geográfico -desconocido hasta aquel entonces- fue un elemento indispensable para entender cómo esto se propagó en el tiempo. A su vez, esto se complementó, con las historias que se describieron desde la primera expedición a Chile dirigida por Diego de Almagro en 1536. Por tanto, Chile como espacio geográfico, para la década de 1540 ya cargaba con una "mala fama", a pesar de no estar habitado. (Esta idea la desarrollamos ampliamente en nuestra tesis de doctorado.) entender que mientras la derribaban me darían lugar para hacer algunos actos de contrición. Y confieso que deseo volver a aquellos peligros dulces" (Medina, 1898: 303) (Subrayados del autor).

El informe del jesuita era una búsqueda de derechos. Era la esperanza de que a los habitantes de un territorio percibido como peligroso se los considerase y premiase de una manera más notoria, por las dificultades de vivir entre tantas distancias y calamidades. Aquel informe que solicitaba ayuda y atención, tenía como objetivo poner en valor una gama de experiencias desastrosas que habían ocurrido en los últimos veinte años en Chile. Era un actualización de sucesos recientes, pero que estaba cargado de recuerdos sobre escenarios similares que venían ocurriendo -para ese entonces- desde hacía más de cien años.

El documento buscaba introducir el conjunto de preocupaciones que existían en aquel "reino" sobre el "Real Ejército del Reino de Chile y sus dos principales ciudades", como también comunicar un nuevo escenario que brotó desde aquella tierra sindicada como de riesgo, incluso, antes de ser habitada. Se trataba de un nuevo "actor", según el jesuita, dentro del teatro de calamidades y desazones con los que se identificaba Chile para esos años: los terremotos.

Los describía como la última gran "desdicha", es decir, como un nuevo elemento dentro de aquel teatro calamitoso, poco considerado por las autoridades españolas. Los terremotos de 1647 (Santiago) y 1657 (Concepción) entraban así al panteón de desgracias bajo el cual se reconocía y representaba a Chile:

"La ultima desdicha que padeció el reino de Chile (quiera Dios que sea la última) fue la del terremoto que asoló la ciudad de la Concepción, segunda en dignidad después de la de Santiago. Y dos horas después de haber derribado sus casas el temblor de tierra y muerto mucha gente, entró la mar y acabo con todo: y fue tan grande este temblor que distando de esta ciudad la de Santiago ochenta leguas llegó allá el temblor tan recio que maltratando todas las iglesias y casas, derribó la iglesia mayor, viniéndose abajo los arcos que hermosamente la componían sin de- 
jar una capilla en que poder decir misa" (Medina, 1898: 296).

El jesuita le indicaba al "León" -nombre que le daba al Rey-, los diferentes acontecimientos considerados como desastrosos y el lugar que tuvo cada movimiento telúrico.

“No desmaye pues Chile puesto en los últimos términos del Occidente, en las desdichas que ha padecido de veinte años a esta parte, porque tiene por rey un león, que aun cuando descansa, tiene los ojos abiertos para ver las repetidas pestes que le han dejado sin gente. El holandés que le quemo la provincia de Chiloé, el temblor que le arruino la ciudad de Santiago [1647], el indio que se rebeló: su lanza que vertió tanta sangre española, tantos niños inocentes, con manifiesto peligro de la honestidad en las unas y de la fe cristiana en todos. La ciudad de San Bartolomé de Chillan que se despobló, el célebre castillo y estado del belicoso Arauco: la estancia del Rey, las misiones de Boroa y Peñuelas. El segundo terremoto que asoló la ciudad de la Concepción [1657], la mar que entro con horrendos bramidos acabando de aniquilar lo que había quedado. No desmayes, vuelvo a decir, Chile, que todas estas calamidades las ven los ojos reales del León que te cupo por rey y señor, y las ve para remediarlas" (Medina, 1898: 296) (Subrayado del autor).

Para el religioso, era coherente presentar a los sismos como contingencias que afectaron a los dos grandes espacios cívicos -Santiago y Concepción-, puesto que era en esos lugares donde se reproducía la vida en policía que esperaba la Monarquía y constituían los límites de lo habitado ${ }^{18}$. Todo el resto del territorio, es decir, lo que había entre aquellas ciudades, fue comprendido desde el siglo XVI y hasta mediados del siglo XVIII, como espacios de riesgo, puesto que eran lugares

\footnotetext{
${ }^{18}$ Ciudades como Coquimbo y La Serena eran pequeñas localidades que dependían de Santiago. La mayor parte de la población vivía en las zonas interiores de esas regiones (valles), puesto que los ataques piratas fueron recurrentes. Esto no permitió un mayor poblamiento para esos años y afectó el desarrollo de las urbes.
}

donde los españoles se encontraban indefensos, sobre todo, ante una emboscada indígena. Por tanto, fueron zonas en donde no se podían apreciar los intereses generales de los españoles, ahí solo se podían apreciar más bien los intereses privados de los europeos (haciendas). Por ello, como veremos más adelante, no se tomaron en cuenta aquellos sismos en donde no se viera afectado alguno de estos polos. La sismicidad chilena, para esos años estuvo vinculada directamente a la idea de ciudad.

Ahora bien, de inmediato surgen una serie de preguntas sobre por qué Arizabalo consideraba a los terremotos una nueva desdicha para Chile: ¿por qué su relato precisaba que fue a partir del terremoto de 1647 y no antes, que los sismos podían ser considerados como un nuevo actor de infortunio? sobre todo, si sabemos que antes de estas fechas también se pueden identificar otros sismos reconocidos desde un punto de vista "oficial". Nos referimos a los movimientos telúricos de 1570 (Concepción) y 1575 (Valdivia).

A diferencia de los terremotos del siglo $X V I I$, los sismos ocurridos durante el siglo $\mathrm{XVI}$, no fueron insertos como grandes eventos desastrosos en el discurso y memoria de los habitantes de aquella época. Los impactos de estos no superaron el plano simbólico, principalmente, porque para esa época ambas "ciudades", tenían poco o nada construido y no eran más que "refugios de guerra" para los españoles. En efecto, ambos lugares -Concepción y Valdivia- entre 1570 y 1575 eran simplemente fuertes de combates en tierras aún sin conquistar $y$, por tanto, eran consideradas como inseguras. Los habitantes eran escasos y existía una falta de medios que no permitían valorizar aquel supuesto patrimonio. La ilusión de presentarse como "ciudades" -pese a ser solo estatuto político- favoreció a que se pensara en ayudarlas, no obstante, entre las autoridades esto no dio fuerza para que fueran valorados como grandes acontecimientos. Esto, debido a que la inestabilidad del lugar había provocado que las ayudas desde el Perú estuviesen más bien limitadas y que el proyecto de expansión en esos sitios fuese limitado.

Es cierto que estos desastres pudieron afectar, en términos muy generales, los inte- 
reses de conquista ${ }^{19}$, pero aquellos eventos quedaron sumidos a ser un argumento más dentro de las peticiones de ayuda que se solicitaba para aquellos años al nuevo Virrey entrante. Esto no quiere decir que estos sucesos fueron infértiles en cuanto a la producción de recuerdos o "lugares de memoria" (Nora, 1997). De hecho, en Concepción tras el terremoto de 1570 se construyó una ermita de la Virgen de las Nieves y que, al parecer, duró por muchos años según el cronista de la época Diego Rosales (Rosales, 1989: 191-192). Sin embargo, la proyección discursiva no permitió que fueran introducidos en las representaciones telúricas o desastrosas. Fueron los historiadores republicanos como Diego Barros Arana o José Toribio Medina los que desde mediados del siglo XIX otorgaron páginas a estos movimientos telúricos y los reinsertaron como eventos originarios la nación, pero aún así no se revalorizó lo sucedido, puesto que las representaciones de las catástrofes no consideraron estos eventos como efemérides a recordar.

Esto no se trató de un tema de menos "intensidades", sino de "seguridades" y significado de los lugares afectados, los cuales para ese entonces, no eran propiedad absoluta de los españoles y su influencia en aquellas zonas era bastante mínima. De hecho, en términos de "intensidad" los eventos habrían sido de una violencia considerable al desestructurar algunas de las geografías de la zona, como sucedió en Valdivia con el maremoto y salida posterior del río. Tampoco se trató de una falta de testimonios, ya que los hubo -aunque en menor grado- y tuvieron la misma fuerza descriptiva que los del siglo XVII y XVIII.

Esto se habría tratado de un tema relacionado con la memoria. Un colectivo no puede identificarse solo en un recuerdo,

\footnotetext{
${ }^{19}$ Coincidimos con Carlos Rojo en que el terremoto pudo afectar la conquista, pero más que nada en términos anímicos y de destrucción de los materiales básicos. Sin embargo, intentar explicar configuraciones discursivas, "cosmovisiones" o hablar de ciudades nos parece excesivo para aquellos tiempos y bastante general. En efecto, la reconfiguración de la conquista de la zona sur sufrió un "terremoto" más fuerte ese mismo año con la disolución de la Real Audiencia en Concepción (cf. Rojo, 2009).
}

no alcanza a reconocerse a sí mismo en él. Como diría Halbwachs, esto solo se puede legitimar y adquiere nitidez en el "mundo social" -marcos sociales-, puesto que requiere de un "espacio" - una ciudad o pueblo- para presentarse (Halbwachs, 1997). El recuerdo como tal cuando se reconoce por el conjunto de individuos que lo pueden identificar. Como en ese entonces, ambas ciudades tenían un mínimo asentamiento español y las decisiones se tomaban en Santiago no se pudo forjar ni legitimar un recuerdo colectivo sobre estos eventos que perdurase en el tiempo.

A su vez, pensamos que estos terremotos no fueron recordados puesto que se trató también de una "estrategia de olvido". Si los terremotos hubiesen sido introducidos como otro gran problema más durante el siglo XVI, difícilmente, se podría pensar que hubiesen Ilegado más españoles a Chile. El recuerdo se invalidó en pos de establecer un olvido para mantener, posiblemente, la estabilidad de un colectivo.

Volviendo al testimonio de Arizabalo, la pregunta más certera sería ¿qué llevó al jesuita a considerar el terremoto de 1647 como el hito que crea un nuevo escenario de desgracias con la cual se podía asociar Chile? Asimismo, emergen otras interrogaciones, sobre cómo poder analizar un tema como el sísmico, si las propias descripciones de las autoridades o referentes religiosos narraban e incluían dentro del escenario catastrófico a diversos actores como el Rey, la Monarquía, o a diferentes espacios y preocupaciones -cristiandad, guerra contra indígenas-.

La insistencia de que Chile era una tierra desamparada, peligrosa y adversa por parte del jesuita fue uno de los tantos ejemplos que podemos apreciar sobre este tipo de tópicos. Es una de las tantas puertas de entrada no solo para descifrar las extensiones que afectaron y agruparon los sismos, sino que también para poder establecer bajo qué parámetros políticos, culturales y espaciales se forjaron las nociones de riesgo y desastre en Chile, que permitieron reconocer a los terremotos como un nuevo actor desastroso un siglo después de la llegada española. 


\section{Terremotos recordados, sismos olvidados $i$ Inicios de una memoria telúrica?}

La noche del 13 de mayo de 1647 permitió consolidar la idea de Chile como una tierra de catástrofes y riesgos. Entre las diez y media y las once de aquella noche se produjo este primer terremoto de importancia para los habitantes de aquellas épocas. Este fue el primero de una serie de sismos considerados como desastrosos dentro de la historia de aquel país. Dentro del período que estudiamos, encontramos otros que tuvieron esta propiedad. Diez años después de este evento "fundador", es decir, el 15 de marzo de 1657, entre las ocho y nueve de la noche un movimiento sísmico destruyó la ciudad de Concepción. Este fue acompañado de un tsunami casi cuatro horas después. Esta "salida del mar" se produjo justo en los momentos en que aquellos que aún tenían "la esperanza de reparar sus casas" vieron cómo el agua subió hasta la plaza de la ciudad (Olivares, 1865: 217).

Hacia el primer tercio del siglo XVIII, el día 8 de julio de 1730, Santiago y Concepción tuvieron que soportar un movimiento telúrico a eso de las cuatro de la mañana. Se trató de tres grandes movimientos de la tierra que destrozaron la arquitectura de ambas ciudades, como indicaba el presidente Gabriel Cano de Aponte ${ }^{20}$. Sin embargo, Santiago como capital y centro de seguridad acaparó, en términos de representación de la catástrofe, una mayor atención. En efecto, lo ocurrido en Concepción se podría interpretar como una tragedia más relevante, ya que se registró un tsunami que por la fuerza del movimiento hizo pensar al Virrey del Perú que este habría nacido desde sus costas:

"el día ocho de julio de este presente año se advirtió en esta mar la nunca vista novedad de elevarse lentamente hasta cubrir las paralelas y huestes que resguardaban

20 “Gabriel Cano Aponte, relación de lo que sucedió y experimento la ciudad de la Concepción y reino de Chile en los temblores de tierra y aguaceros, Santiago 20 de julio de 1730", Archivo General de Indias, CHILE, 145, № 6. (A partir de ahora, AGI, CHILE). sus ímpetus retirándose algunos pasos con la misma lentitud que duro todo aquel día y mucha parte del siguiente cuyo suceso que aquí solo fue amago de la justicia divina reventó en el reino de Chile" 21 .

Veintiún años después, el 25 de mayo de 1751 se produjo en la zona de Penco o Biobío un terremoto y tsunami que destruyó la ciudad por completo: "el mar se ausento precipitadamente de sus riberas dejando toda su bahía (que es de 3 lenguas) en seco, pero como a los sietes minutos volvió con grandísima fuerza encrespando ola sobre ola con tanta altura que excedió sus límites supuro y corono toda la ciudad entrando con más violencia que la carrera de un caballo"22. "El primer golpe" -como decían los habitantesfue aproximadamente a las una y treinta de la mañana, el primero de una serie de movimientos telúricos de gran envergadura. Se relataba que el agua subió en algunos lugares hasta 4 varas: "subió tanto que no le falto dos cuadras para llegar a los cerros". La "furia" del agua inundó las casas tanto de autoridades, los vecinos, como de los más pobres, siendo "el barrio Ilamado Cantaranas fue por donde con más libertad ejecuta su furia" 23 .

Solo estos cuatro terremotos habrían sido insertos dentro del discurso catastrófico. Puntualizar que solo fueron estos cuatro sismos los considerados como los sismos recordados, no es una arbitrariedad de nuestra parte, sino fue una realidad descubierta a partir de las memorias representadas y transmitidas por los diferentes pobladores y autoridades del período. Existieron un sinnúmero de otros sismos que no se consideraron como catástrofes y que ocurrieron antes y posteriormente a 1647, pero que no fueron puestos en valor (Cuadro $\left.\mathrm{N}^{\circ} 1\right)$.

21 "Carta del Marquez de Castelfuerte a SM sobre el terremoto de 8 de julio de 1730 en Chile. Lima, 19 noviembre de 1730", AGI, CHILE, 145, No 3, fjs. $14-15 \mathrm{v}$.

22 "Tosca narración de lo acaecido en la ciudad de la Concepción de Chile el 24 de mayo de 1751" (Gay, 1852: 484-491).

23 "Relación de lo sucedido en la ciudad de Concepción de Chile en el temblor e invasión del mar el día 25 de mayo de 1751, entre la una y dos de la mañana" (Davin, 1755). 
Cuadro $\mathrm{N}^{\circ} 1$

Terremotos más renombrados desde el siglo XIX

\begin{tabular}{|l|l|}
\hline 8 de febrero de 1570 & Concepción \\
\hline 16 de diciembre de 1575 & Valdivia \\
\hline 13 de mayo de 1647 & Santiago \\
\hline 15 de marzo de 1657 & Concepción \\
\hline 8 de julio de 1730 & Santiago-Concepción \\
\hline 25 de mayo de 1751 & Concepción \\
\hline
\end{tabular}

Fuente: Elaboración propia.

El resto de movimientos de la tierra que ocurrieron durante esos siglos, no fueron considerados como terremotos, sino como pequeños sismos, porque no cumplieron con los requisitos que las autoridades españolas establecieron sobre cuándo se podía denominar o no un movimiento telúrico de esta manera. En este sentido, se podría decir que hubo un monopolio de los epicentros y de los recuerdos de estos terremotos, el cual estuvo determinado, principalmente, por el hecho de si afectaban o no a los únicos dos centros urbanos que funcionaban como ciudades, es decir, los lugares en donde se podía apreciar y reproducir el sistema monárquico (espacios de seguridad).

Por los motivos esgrimidos, pensamos que se quitó importancia, se ocultó o, simplemente, no se consideraron relevantes aquellos sismos que no afectaron directamente la seguridad de las dos grandes ciudades. No existen registros desde las haciendas que nos permitieran decir lo contrario, aunque el hecho que los vecinos fueran "vecinos feudatarios", es decir, que al mismo tiempo pertenecieron al campo y la ciudad, nos permite verificar que gran parte de los habitantes a lo largo de Chile se vieron afectados de alguna manera (Góngora, 1970; Mellafe, 1981). Esto no quiere decir que no fueran contabilizados o se desconocieran los efectos de estos sismos. Insistimos, mientras no se destruyeran o afectarán ambos focos de "seguridad", poco se escribió sobre su existencia, lo que trajo como consecuencia que no fueran recordados y se generaran escasas o nulas representaciones sobre estos. Variados ejemplos permiten certificar el olvido de esta cantidad importante de movimientos de la tierra. Uno de estos casos fue el sismo de 1639 que destruyó parte de la iglesia de Coquimbo y otras casas, causando destrozos importantes para esa pequeña ciudad, pero que poco o nada se habló y conoce de él ${ }^{24}$.

En otras palabras, estos sismos se pudieron "esconder" mientras sus efectos no perturbaran el conjunto de intereses de los dos referentes urbanos. Un ejemplo de esto ocurrió en la ciudad de Valparaíso. El día 14 de mayo de 1723, la ciudad vivió un gran temblor que provocó la destrucción de un pequeño fuerte de defensa y de algunos lugares de comercio. No obstante, como este no alteró mayormente el abastecimiento de Santiago ni se detuvo el comercio con el resto del Reino, no se generó una mayor alarma. El sismo solo se observó como un hecho que podía interferir la defensa del puerto, ante una posible venida de los "enemigos del mar"25. Un caso similar, aconteció el 24 de diciembre de 1737. Una gran sacudida en toda la zona centro sur de Chile y cuyo posible epicentro habría sido en Valdivia sucedió ese día. Sus consecuencias más relevantes sucedieron en un plano más bien local y no afectaron a la totalidad del reino. En efecto, tras esta "sacu-

24 "Cuenta de la Real Audiencia de Chile sobre las tierras de Coquimbo. 21 de Mayo de 1651", AGI, 12, R.4, N.62.

${ }^{25}$ Fue el presidente de Chile de aquella época, Gabriel Cano Aponte quien informó de esta situación a las autoridades reales: "Señor, hallándome con noticia que el ingeniero que vuestra majestad sirvió enviar en galeones a fin de reconocer las fortalezas del Perú, las de Valdivia y las de la frontera de este reino, Ilego a Lima, escribió al Virrey le mandase transportar a esta ciudad o a la de la Concepción para que con mi asistencia veamos lo que se debe hacer en ellas y especialmente en el castillo de Valparaíso que casi le dejo arruinado un temblor grande que sobrevino la noche del día catorce de mayo del año pasado y aunque por su mala colocación y construcción es poco menos que inútil, sin embargo sirve de algún respeto para los enemigos del mar por cuyo motivo he dispuesto se vayan reparando las ruinas con alguna plata que a este fin hice separar del ultimo situado y se continuara en ellas si el Virrey remite tres mil pesos que me escribió enviara para este efecto..". "El presidente de Chile, Gabriel Cano Aponte informa a SM el Rey que ha escrito al Virrey del Perú sobre asuntos de galeones y fortificaciones, Santiago 16 marzo de 1723", Biblioteca Nacional de Chile, Manuscritos Sala Medina, Rollo 34, Tomo 180-181, Pieza 3973, fjs. 7-8. (A partir de ahora BNCh, MsM). 
dida" las autoridades decidieron fortificar la ciudad para poder evitar mayores percances y sentirse más protegidos ante los repetidos de ataques de naciones extranjeras y temblores.

Esta misma catástrofe, en términos discursivos, quedó sumida a ser uno más de los acaecimientos negativos que ocurrieron posteriormente al terremoto de 1730. El 6 de febrero de 1741, el Consejo de Indias envió a Chile una carta sobre los reparos de la catedral de Concepción y otros asuntos surgidos tras el terremoto de 1730, señalando de manera sucinta los efectos que tuvo aquel temblor (1737). Esto demuestra, que se le consideró como un movimiento de tierra que debía asociarse a lo ocurrido en 1730. Por tanto, quedó sumergido en el recuerdo de este.

"En cartas de 30 de enero y 3 de mayo de 1739 representaron Don Joseph Manso Presidente, gobernador y capitán general del Reino de Chile y el reverendo obispo de la ciudad de la Concepción el formidable temblor de tierra que se padeció en esta ciudad el día 24 de diciembre de 1737 señaladamente en lo material del edificio de la catedral que desunidas sus trabazones, retirados los puntales que le mantenían e inclinadas afuera las paredes quedo en estado de inservible, y sin que se pudiese entrar en ella, sin manifiesto peligro de la vida..." 26

Otro tópico a considerar a partir de lo expresado por los testimonios, es la distinción que desde aquellos años hacen los habitantes de Chile con respecto a utilización de palabras para explicar cuándo sucede un terremoto. Desde esos años, existe una diferencia entre lo que es un sismo (temblor) y lo que es un terremoto. Por ejemplo, para 1575 no era clara la diferencia entre ambas palabras, ni siquiera en un mismo testimonio: "a las tres horas de la tarde vino poco más o menos un gran temblor y terremoto... todo el pueblo caído por el suelo y todas las iglesias tanto que hasta paredes muy bajas que se comen-

26 "Carta del Consejo de Indias al Rey sobre los reparos de la catedral de Concepción y otros asuntos surgidos tras el terremoto de 1730. Madrid, 6 de febrero de 1741", AGI, CHILE, 69, documento No 41 . zaban a labrar se cayeron de tan recio como fue el temblor"27. Un siglo y medio después tampoco era claro si la palabra terremoto o temblor englobaba una gran catástrofe o también una situación menor. El 26 de mayo de 1722 el Cabildo de Santiago dejaba constancia de un terremoto ocurrido en la ciudad el día 24 de mayo del mismo año a las cuatro de la mañana, el cual no fue considerado como una catástrofe en el recuerdo ${ }^{28}$. No obstante, se actuó como si hubiese ocurrido un terremoto. Los vecinos demandaron la coordinación de las distintas esferas de poder para mantener el orden. Posterior a esto, el Cabildo de Santiago solicitó la verificación del estado de las paredes, el control de los precios y se terminó por hacer una procesión al Cristo Crucificado quien era abogado de los temblores:

"se juntaron en la sala de su ayuntamiento en Cabildo extraordinario con el motivo del terremoto que se experimento el día veinte y cuatro del corriente a las cuatro de la mañana para tratar sobre las cosas tocantes al bien común y así juntos y congregados los dichos señores el dicho señor gobernador leyó un auto de buen gobierno sobre que no se altere el precio de los peones y albañiles que se necesiten para el reparo de los edificios que se han lastimado en la ciudad y que el valor del millar de teja no se altere su precio a la cantidad de veinte y cinco pesos puesta en cargadero so pena que en dicho auto se contienen y consultó sobre si sería conveniente que se pusiese en ejecución y todos los señores de unánime acuerdo vinieron en ello"29.

27 “Relación verdadera de lo que acaeció en Chile durante el viaje de Drake suscrita en 16 de Diciembre de 1575. sin nombre de autor", BNCh, MsM, Rollo 2, Tomo 88, Pieza 1212, fjs. 259-262.

${ }^{28}$ Un texto que intenta estudiar los terremotos más relevantes para el Virreinato del Perú ocurridos en los siglos XVII y XVIII plantea que el 25 de marzo de 1725 también se habría sentido un terremoto en Santiago de Chile (Barrenechea, 1725).

29 "Actas del Cabildo de 26 de mayo de 1722", ACS, $\mathrm{CHCh}$, Santiago, Editorial Universitaria, Tomo L, 1942, p. 370; Otro temblor de este tipo habría ocurrido el de 9 de Julio de 1690 (Palacios, 2009). También podríamos señalar otro sismo que sí fue considerado terremoto, pero que al no pertenecer a la gran zona de seguridad no tuvo un gran eco en 


\section{Consideraciones finales}

Los movimientos telúricos que no fueron descritos y representados posteriormente, fueron hechos que de todas maneras impactaron y generaron daños en las localidades. Sin embargo, no alcanzaron a valorizarse en el colectivo o, mejor dicho, por las autoridades para que se creara un relato que pudiera descubrirlas como una catástrofe del Reino. Una catástrofe fue considerada como tal, cuando un conjunto de hechos nefastos pudieron ser descritos, relatados y transmitidos posteriormente.

Posiblemente, la gran mayoría de estos sismos desechados podrían considerarse como desastres porque aportaron destrucción. No obstante, hubo otros motivos o eventos que no permitieron posicionarlos como un verdadero "problema". La fuerza ejercida desde el plano político se superpuso y marcó la lectura y olvido de estos eventos. Así se estableció tanto el orden como el contenido de lo que se debía representar tras una de estas catástrofes.

La perspectiva presentada tuvo el interés de mostrar, panorámicamente, algunos de los temas que pueden servir como base para establecer preguntas relacionadas a las memorias asociadas al tópico telúrico y los actores que las han protagonizado y utilizado. A su vez, pueden constituir un camino para verificar hasta qué punto catástrofes como los terremotos se han convertido en hilos conductores para leer e interpretar la historia de Chile.

Probablemente, jamás se encontrará el punto exacto de partida sobre los orígenes de estas memorias, sin embargo, se pueden delinear las formas iniciales cómo se han construido o desarrollado estas, mediante estudios multidisciplinarios entre las ciencias, en donde la historia también tiene una voz, puesto que una parte de ella busca la verdad.

\footnotetext{
su transmisión. Nos referimos a un terremoto que habría ocurrido en la zona de Coquimbo. Ver el testimonio de "Juan Sotomayor Sobre el terremoto de Coquimbo del 30 de marzo de 1796". Escrito en La Serena en 1796, Archivo Nacional de Chile, Fondo Capitanía General de Chile, Volumen 1032, fj. 682.
}

\section{Referencias bibliográficas}

ALBOUY, F. Le temps des catastrophes. Paris: Descartes et Cie ed, 2002.

BARRENECHEA, J. Relox astronómico de temblores de la tierra: secreto maravilloso de la naturaleza, descubierto y hallado. Lima: Imprenta Antuerpiana, 1725.

BRAUDILLARD, J. L'économie politique et la mort. Revista Traverses, 1975, p. 22.

CANDAU, J. Antropologie de la mémoire. Paris: Armand Colin, 2005.

CLAVANDIER, G. La Mort collective: pour une sociologie des catastrophes. Paris: CNRS Éditions, 2004.

CLAVANDIER, G. Faire face à la catastrophe. Paris: La Vie des idées, 2011. Disponible en Internet: http://www.laviedesidees.fr/Faireface-a-la-catastrophe.html

COLLAS-HEDDELAND, E.; COUDRY, M.; KAMMERER, O.; LEMAITRE, A. \& MARTIN, B. Pour une histoire culturelle du risque : genèse, évolution, actualité du concept dans les sociétés occidentales. Strasbourg : Éditions Histoire et anthropologie, 2004.

DAUPHINE, A. Risques et catastrophes: observer, spatialiser, comprendre, gérer. Paris: Armand Colin, 2004.

DAVIN, D. Cartas edificantes, y curiosas, escritas de las missiones estrangeras, y de levante por algunos missioneros de la Compañía de Jesús. Madrid: Imprenta de la Viuda de Manuel Fernández, 1755.

DOUGLAS, M. Risk and Blame: essays in cultural theory. London and New York: Routledge, 1992.

DUPUY, J-P. Pour un catastrophisme éclairé : quand l'impossible est certain. Paris: Seuil, 2002.

FANTINI, B. La perception du risque sanitaire dans I'histoire. In: WALTER, F. \& FANTINI, B. \& DELVAUX, P. Les cultures du risque (XVIe - XXle siècle). Genève: Presses D'histoire Suisse, 2006. 
FERNÁNDEZ, M. Arica 1868: un tsunami y un terremoto. Santiago de Chile: Universidad de Tarapacá, 2007.

FOUCAULT, M. Dits et écrits. Paris: Edition Quarto Gallimard, 2001.

GAY, C. Historia física y política de Chile. Documentos sobre la historia, la estadística y la geografía. Paris: Chez I'auteur, 1852.

GARCÍA, V. Introducción. En: GARCÍA, V. (coordinador). Historia y Desastres en América Latina. México: Centro de investigaciones y estudios superiores en antropología social, Red de estudios sociales en prevención de desastres en América Latina (RED), 1996, p. 5-22.

GARCÍA, V. Enfoques teóricos para el estudio histórico de los desastres naturales. En: MASKREY, A. (compilador), Los desastres no son naturales. México: Red de Estudios Sociales en Prevención de Desastres en América Latina, 1993, p. 128-137.

GILBERT, C. Le poids du virtuel à propos des catastrophes. Revista Traverses, 1998, No 44-45, p. 157-163.

GIRARD, V. \& LANGUMIER, J. Risques et catastrophes: de I'enquête de terrain à la construction de I'objet. Revista Genèses, 2006, No63, p.128-141.

GÓNGORA, M. Encomenderos y estancieros. Estudios acerca de la constitución social aristocrática de Chile después de la conquista. 1580-1660. Santiago de Chile: Universidad de Chile, 1970.

HALBWACHS, M. La Mémoire collective. Paris: Albin Michel, 1997.

HARTOG, F. \& REVEL, J. (directores). Les Usages politiques du passé. Paris: Éditions de I'EHESS, 2001.

HARTOG, F. Régimes d'historicité, Présentisme et expériences du temps. Paris: Seuil, 2003.

JEUDY, H-P. Le Désir de catastrophe. Paris: Aubier, 1990.
JEUDY, H-P. Préface. Écrire la catastrophe. In: THOMAS, C. \& MERCIER-FAIVRE, A-M. (directores). L'invention de la catastrophe au XVIIle siècle. Du châtiment divin au désastre natural. Genève: Librairie Droz, 2008.

LÓPEZ, E. La memoria del terremoto de 1647 en la obra de los historiadores liberales. Revista de Historia Social y de las Mentalidades, 2011, Vol. 15, No 2, p.137-164.

MASSARD-GUILBAUD, G. Pour une histoire environnementale de I'urbain. Revista Histoire urbaine, 2007, No 18, p. 5-21.

MEDINA, J-T. Biblioteca Hispano Chilena. Santiago de Chile: Impreso y Grabado en Casa del Autor, 1898.

MELLAFE, R. Latifundio y poder rural en Chile de los siglos XVII y XVIII. Revista Cuadernos de Historia, 1981, N 1, p. 87-108.

MENONI, S. Pianificcazione e incertezza. Elementi per la valutazione e la gestione dei rischi territoriali. Milan: Franco Angeli, 1997.

NOVEMBER, V. Les Territoires du risque: le risque comme objet de réflexion géographique. Bern \& New York : P. Lang, 2002.

NORA, P. (director). Les lieux de mémoire. Paris: Gallimard, 1997.

O'DEA, M. Le mot "catastrophe". In : MERCIER-FAIVRE, A-M. \& THOMAS, C. (director). L'invention de la catastrophe au XVIIle siècle. Du châtiment divin au désastre naturel. Genève : Librairie Droz, 2008, p. 35-48.

OlivareS, M. Historia de la Compañía de Jesús en Chile (1593-1736). Santiago de Chile: Imprenta del Ferrocarril, 1865.

ONETTO, M. Apuntes sobre memorias sensoriales y catástrofes. Chile, siglos XVIXVIII. Revista de Historia Iberoamericana, 2011a, No 1, p. 50-66. Disponible en internet: http://revistahistoria.universia.net/pdfs_ revistas/articulo_147_1309296844734.pdf

ONETTO, M. Replantear los "aconteceres, replantear los espacios en Chile. Revista de Historia Social y de las Mentalidades, 2011b, Vol. 2, No 15, p. 17-39. 
ONETTO, M. Tremblements de Terre dans le Jardin d'Eden. Désastre, Mémoire et Identité au Chili (XVIe-XXle siècle). París: Tesis para optar al grado de Doctor en Histoire et Civilisations en I'École des Hautes Études en Sciences Sociales, 2013

PALACIOS, A. El gran terremoto de 1730: la experiencia santiaguina frente a la catástrofe. Revista Temas Americanistas, 2009, № 22 p.1-18.

PETIT-BREUILH, M. Naturaleza y Desastres en Hispanoamérica. La Visión de los Indígenas. Madrid: Silex Ediciones-Universidad, 2006.

PIGEON, P. Réflexions sur les notions et les méthodes en géographie des risques dits naturels. Revista Annales Géographie, 2002, $N^{\circ}$ 627-628.

QUENET, G. Les Tremblements de terre aux XVIIe et XVIIIe siècles: la naissance d'un risque. Seyssel: Champ Vallon, 2009.

QUENET, G. La catastrophe, un objet historique? Revista Hypothèses, 1999, p. 13-20.

QUÉ RÉ, L. Entre foit et sens, la dualité de l'evénement. Réseaux, 2006, No 139, p. 183-218.

RAMÓN, E. La sociedad Santiaguina frente a una Catástrofe 1647-1651. Boletín de Historia y Geografía, 1998, № 10, p. 57-68.

RIQUELME, A. y SILVA, B. Una identidad terremoteada. Chile en 1960. Revista Historia Iberoamericana, 2011, Vol. 4, № 1. Disponible en Internet: http://revistahistoria.universia. net/verRevista.jsp?idRevista $=18$

ROJO, C. Terremoto de 1575: Representaciones y discursos en la capitanía general de Chile en el Siglo XVI. Revista Temas Americanistas, 2009, p. 67-90.
ROSALES, D. Historia general del reino de Chile: Flandes indiano. Santiago de Chile: Editorial Andrés Bello, 1989.

SIGNORELLI, A. Catastrophes naturelles et réponses culturelles. Revista Terrain, 1992, $\mathrm{N}^{\circ} 19$, p. 147-158.

TODOROV, T. La mémoire devant I'histoire. Revista Terrain, 1995, No 25, p. 112.

VALENZUELA, J. El terremoto de 1647: experiencia apocalíptica y representaciones religiosas en Santiago colonial, En: VALENZUELA, J. (editor). Historias urbanas. Homenaje a Armando de Ramón. Santiago de Chile: Ediciones Universidad Católica de Chile, 2007, p. 27-65.

VALENZUELA, J. Relaciones jesuitas del terremoto de 1730: Santiago, Valparaíso y Concepción. Cuadernos de Historia, 2012, $\mathrm{N}^{\mathrm{o}} 37$, p. 185-224.

VIRILIO, P. L'accident originel. Paris: Galilée, 2005.

VIRILIO, P. L'Université du désastre. Paris: Galilée, 2007.

WALTER, F. Catastrophes. Une histoire culturelle. XVIe- XXIe siècle. Paris: Seuil, 2008.

WEINER, D. A death-defying attempt to articulate a coherent definition of environmental history. Revista Environmental History, 2005, p. 404-420.

WHITE, R. The nationalization of nature. Revista Journal of American History, 1999, Vol. 3, Nº6, p. 976-989. 
